\title{
Alternative approaches to evaluation of cow efficiency
}

\author{
M.D. MacNeil ${ }^{1,2,3 \#}$, M.C. Mokolobate ${ }^{1,2}$, M.M. Scholtz ${ }^{1,2}$, F.J. Jordaan' \& F.W.C. Neser ${ }^{2}$ \\ ${ }^{a}$ Agricultural Research Council, Private Bag X2, Irene 0062, South Africa \\ ${ }^{b}$ University of the Free State, P.O. Box 339, Bloemfontein 9300, South Africa \\ ${ }^{\circ}$ Delta G, 145 Ice Cave Road, Miles City, MT 59301, USA
}

(Received 21 July 2016; Accepted 11 December 2016; First published online 26 January 2017)

\author{
Copyright resides with the authors in terms of the Creative Commons Attribution 4.0 South African License. \\ See: http://creativecommons.org/licenses/by/4.0/za \\ Condition of use: The user may copy, distribute, transmit and adapt the work, but must recognize the authors and the South African \\ Journal of Animal Science.
}

\begin{abstract}
The purpose of this study was to evaluate alternative expressions of genetic merit for cow efficiency. Weights of Pinzgauer cattle taken at birth, weaning, and maturity were extracted from the South African National Database. Average daily gain from birth to weaning (ADG) and cow weight (CWT) were analyzed with a multi-trait mixed model. The model included direct and maternal genetic effects, a permanent environmental effect attributable to dams on ADG, a direct genetic effect and a permanent environmental effect attributable to there being multiple observations from the same cow on CWT as random effects. Heritability estimates for direct and maternal additive effects on ADG were $0.27 \pm 0.04$ and $0.06 \pm 0.02$, respectively. The estimated heritability for CWT was $0.45 \pm 0.06$. Estimates of repeatability for ADG and CWT were 0.42 and 0.67 , respectively. Estimated breeding values based on the preceding results and using the maternal genetic effect on ADG as a proxy for the direct genetic effect on milk production were combined in six indexes of cow efficiency. These indexes sought to increase output and decrease input simultaneously, to increase output holding input constantly, and to hold input constant while decreasing input. The diversity of emphasis applied across these indexes suggests the need for due diligence in developing breeding objectives for improvement of cow efficiency. Indexes that are consistent with the econometric definition of efficiency and seek to simultaneously increase output and reduce input are recommended.
\end{abstract}

Keywords: genetic parameters, multiple trait selection, Pinzgauer, selection index

\#Corresponding author: macneil.deltag@gmail.com

\section{Introduction}

What is meant by 'cow efficiency'? In econometrics, efficient production is characterized by producing the greatest value at the lowest possible cost (Peterson, 1974). Thus, economists are concerned with the trade-off of outputs with inputs, which is consistent with the concept of selection index. In engineering, efficiency is viewed as producing maximum output from a given supply of inputs (Peterson, 1974). This definition can be seen as being parallel with residual gain (Koch et al., 1963). For a beef cow, annual efficiency may be defined by the relationship between mass of calf produced and the feed inputs required to sustain the cow and allow her to provide for her calf. Historically, this relationship has been quantified by the ratio of calf weight at weaning to cow weight (CWT) (Dickerson \& Grimes, 1947; Davis et al., 1983; Frahm \& Marshall, 1985). These ratio measures have theoretical defects that make them undesirable as a basis for genetic improvement (Gunsett, 1986; Iwaisaki, 1989). Dinkel \& Brown (1978) and MacNeil (2005), among others, have also argued that this commonly used ratio measure of cow efficiency is flawed. However, Lin (1980) has developed economic weights for use in a linear selection index to improve objectives, which are defined as ratios, such as the biological efficiency metric calf weight/cow weight.

Dinkel \& Brown (1978) and Kirkpatrick et al. (1985), among others, developed equations to predict the ratio of calf weight produced to feed consumed by the dam and its progeny. This measure of biological efficiency is consistent with the current recommendation of Walmsley et al. (2016). Equations that predict biological efficiency defined thusly, which include both weaning weight of progeny and weight of the dam as independent variables, performed best when applied to data that were not used in their development (Kirkpatrick et al., 1985). Thus, as postulated by MacNeil \& Mott (2000), traits currently measured by at least some seedstock breeders explain a reasonably large proportion of the variation in cow feed intake. Therefore, it is currently feasible to evaluate the genetic components for milk production (or maternal weaning weight) (MacNeil et al., 2006) and cow size in a multi-trait system of national cattle evaluation 
(MacNeil \& Mott, 2000; MacNeil, 2005). Hence, selection indexes that use these results may facilitate genetic improvement in cow efficiency. Therefore, the current objective is to examine a system of multiple trait genetic evaluation for weaning weight and CWT and evaluate alternative indexes of efficiency using data from South African Pinzgauer cattle.

\section{Materials and Methods}

Data recorded for the Pinzgauer breed in the national database were extracted for use in this study. Traits of interest were CWT, and the difference between progeny weaning and birth weights divided by age at weaning (ADG). The calves were reared in 420 contemporary groups as defined by herd, year, and weaning date. Cows were weighed in 188 of these contemporary groups. In all, 6005 calves had records and were the progeny of 2692 dams. An average of 2.0 weights was recorded for 1255 of the cows and each dam present in the data produced an average of 2.4 progeny. A total of 351 sires with an average of 18.6 progeny each were represented in the data.

The generation number (GN) of each animal was calculated as:

$$
\mathrm{GN}=\left(\mathrm{GN}_{\mathrm{s}}+\mathrm{GN}_{\mathrm{d}}\right) / 2+
$$

Where $\mathrm{GN}_{\mathrm{s}}$ and $\mathrm{GN}_{\mathrm{d}}=$ generation numbers of the sire and dam, respectively (Brinks et al., 1964). Generation number was assumed to be zero for all animals for whom both parents were unknown.

Data were analysed with multiple-trait derivative free restricted maximum likelihood (MTDFREML) (Boldman et al., 1993). Fixed independent variables in the model for CWT were contemporary group and age (2-11 yr). Random independent variables included in the model for CWT were an additive direct effect and a permanent environmental effect to account for repeated measures. The model for ADG likewise included fixed independent variables for contemporary group and cow age and, in addition, the fixed effect of sex of calf (male or female).Random effects that were included in the model of ADG were direct and maternal additive effects, and a permanent environmental effect because of the dam. The pedigree that was used to calculate relationships among animals included 26231 animals and was on average 3.9 generations deep.

If the ratio of preweaning gain ( $\left.P W G=205^{\star} A D G\right)$ to $C W T$ was considered an indicator of cow efficiency, economic weights for the linear index of numerator and denominator were calculated following Lin (1980). For this purpose, the EBV for gain from birth to weaning at $205 \mathrm{~d}$ was:

$$
E B V_{P W G}=205\left(E B V_{A D G_{d}}+E B V_{A D G_{m}}\right)
$$

with $E B V_{A D G_{d}}$ and $E B V_{A D G_{m}}$ = the direct and maternal additive effects on ADG. Following Morley (1955) and Kennedy et al. (1993) alternative restricted indexes to improve efficiency by increasing PWG while holding CWT constant or by holding PWG constant and reducing CWT were calculated from the (co)variance components.

These indexes use CWT as a proxy for feed consumption and thus are a simplification relative to improvement of cow efficiency. Addressing genetic improvement of cow efficiency more directly, in the context of the present study, requires an equation to predict feed intake from the genetic effects that have been estimated. Anderson et al. (1983) present one such equation in which the independent variables include CWT and milk. To use the present results with this equation requires the regression of milk yield on ADG. The covariance of gain and milk and the variance of milk from MacNeil et al. (2006) indicate that 36.5 $\mathrm{kg}$ milk would be required to produce $1 \mathrm{~kg}$ calf gain. Then assuming the equivalence of maternal effects on PWG and milk production (Meyer et al., 1994; Miller \& Wilton, 1999; MacNeil \& Mott, 2000) the equation from Anderson et al. (1983) to predict daily feed intake (TDN) could be transformed as follows:

$$
T D N=4.6856+0.0030\left(\mu_{C W T}+E B V_{C W T}\right)+1.8542\left(\mu_{A D G}+E B V_{M}\right)
$$

An additional set of three indexes for cow efficiency, corresponding to those described above, were calculated using predicted TDN intake as a more direct measure of input. Correlations among the indexes were calculated to describe outcomes resulting from evaluations based on these indexes using the sires with progeny in the Pinzgauer data.

\section{Results and Discussion}

Means and standard deviations for preweaning ADG and CWT were 0.78 and $1.09 \mathrm{~kg} / \mathrm{d}$, and 521.8 and $55.4 \mathrm{~kg}$, respectively. Thus, following Lin (1980), the index to improve cow efficiency, defined as a ratio of PWG to CWT, was: 


$$
I=E B V_{P W G}-0.31 E B V_{C W T}
$$

For an individual characterized by $E B V_{C W T}=E B V_{M}=0.0$, predicted daily TDN consumption $=7.69 \mathrm{~kg}$ and with standard deviation $=0.39$. Thus, the index $\left(I^{\prime}\right)$ to improve cow efficiency defined as the ratio of PWG to annual TDN intake was:

$$
I=E B V_{P W G}-0.0257 E B V_{T D N}
$$

wherein:

It follows that:

$$
E B V_{T D N}=365\left(0.0030 E B V_{C W T}+1.8542 E B V_{A D G_{m}}\right)
$$

$$
\begin{gathered}
I^{\prime}=205\left(E B V_{A D G_{d}}+E B V_{A D G_{m}}\right)-9.3805\left(0.0030 E B V_{C W T}+1.8542 E B V_{A D G_{m}}\right) \\
I^{\prime}=205 E B V_{A D G_{d}}+187.6 E B V_{A D G_{m}}-0.0281 E B V_{C W T}
\end{gathered}
$$

In the data used by Anderson et al. (1983) CWT contributed very little to the prediction of cow efficiency (Dinkel \& Brown, 1978). This result provides a plausible explanation for the relatively small coefficient for CWT in Equation 2 relative to Equation 1.

Estimates of variance components and parameters derived from them are presented in Table 1. Estimates of the covariances of the direct effect on CWT with direct and maternal additive effects on gain from birth to weaning were 396.3 and 45.9, respectively, and the corresponding estimates of genetic correlation were $0.70 \pm 0.00$ and $0.17 \pm 0.00$, respectively. The covariance of direct and maternal additive effects on PWG was essentially nil and therefore constrained to 0.0 in the final analysis.

Table 1 Estimates of variance components ${ }^{\mathrm{a}}$, direct $\left(h_{a}^{2}\right)$ and maternal $\left(h_{a}^{2}\right)$ heritability and repeatability $(r)$ for gain from birth to weaning and cow weight of Pinzgauer cattle

\begin{tabular}{lccccccc}
\hline Trait & $\sigma_{a}^{2}$ & $\sigma_{m}^{2}$ & $\sigma_{p e}^{2}$ & $\sigma_{r}^{2}$ & $h_{a}^{2}$ & $h_{m}^{2}$ & $r$ \\
\hline Preweaning gain & 233.7 & 54.2 & 77.7 & 500.9 & $0.27 \pm 0.04$ & $0.06 \pm 0.02$ & 0.42 \\
Cow weight & 1386.0 & & 669.4 & 1011.7 & $0.45 \pm 0.06$ & & 0.67
\end{tabular}

${ }^{\mathrm{a}} \sigma_{a}^{2}$ : variance of the direct additive effect; $\sigma_{m}^{2}$ : variance of the maternal additive effect; $\sigma_{p e}^{2}$ : variance of permanent environmental effect due to dams on preweaning gain or repeated records of cow weight; $\sigma_{r}^{2}$ : residual variance.

The restricted selection index $\left(I_{r}\right)$ to genetically improve PWG while holding CWT constant is:

$$
I_{r}=E B V_{P W G}-0.32 E B V_{C W T}
$$

Similarly, the restricted selection index $\left(I_{r}^{\prime}\right)$ that provides for genetic improvement of PWG while holding the predicted feed intake constant is:

$$
I_{r}^{\prime}=E B V_{P W G}-0.26 E B V_{T D N}
$$

This index is equivalent to selection on residual gain (Kennedy et al., 1993), and is similar to its unrestricted counterpart. Obviously, decreased CWT might be sought in the interest of reducing feed requirements, while maintaining PWG. The restricted selection index $\left(I_{r *}\right)$ that accomplishes this is:

$$
I_{r *}=E B V_{P W G}-0.65 E B V_{C W T}
$$

Finally, the restricted selection index $\left(I_{r *}^{\prime}\right)$ that is anticipated to reduce TDN without reducing PWG is:

$$
I_{r *}^{\prime}=E B V_{P W G}-0.88 E B V_{T D N}
$$

Cow efficiency as represented here is only one part of the biological efficiency of a beef production system. Successful reproduction is probably the most important component of beef production system 
efficiency (MacNeil et al., 1994; Laske et al., 2012; Pravia et al., 2014). However, it has been ignored here and the present results pertain to cows that wean calves. Previous studies provide precedence for consideration of this endpoint (Mwansa et al., 2002; Walmsley et al. 2016). However, there may be merit in considering endpoints closer to harvest in indexes to improve efficiency or profitability of the entire production system (MacNeil \& Newman, 1994; Walmsley et al., 2016).

A summary of statistics describing the relative emphasis placed on the direct and maternal genetic effects on preweaning ADG and direct genetic effects on CWT in each of the indexes is presented in Table 2. The diversity of emphasis applied across these relatively simple indexes, each presumably predictive of biological efficiency, suggests the need for due diligence in developing breeding objectives. It is common knowledge that restricted indexes are less efficient in guiding genetic improvement than their unrestricted counterparts. Thus, Indexes 1 and 2 would be preferable to the others. The discrepancies in relative emphasis between these two indexes illustrate the uncertainty that arises from using CWT as a proxy for feed intake (Kirkpatrick et al., 1985), as well as the need to consider the energy cost of milk production (Ferrell \& Jenkins, 1984), in addition to its beneficial effect on calf performance. Further, the information that has been drawn together here in order to construct these indexes makes any specific population of inference elusive. If South African beef production is to be based on adapted indigenous breeds (Maule, 1973; Assan, 2012; Scholtz \& Theunissen, 2010), a comprehensive evaluation of those resources as dam lines seems warranted and should allow for development of breed-specific breeding objectives and selection indexes to improve maternal efficiency.

Table 2 Relative emphasis (\%) of direct and maternal genetic effects on preweaning gain and direct genetic effects on cow weight in six indexes of efficiency to weaning

\begin{tabular}{|c|c|c|c|c|c|c|c|c|c|c|c|c|c|}
\hline \multirow{3}{*}{ EBV } & \multirow{3}{*}{ Genetic SD } & \multicolumn{12}{|c|}{ Index number } \\
\hline & & \multicolumn{2}{|l|}{1} & \multicolumn{2}{|l|}{2} & \multicolumn{2}{|l|}{3} & \multicolumn{2}{|l|}{4} & \multicolumn{2}{|l|}{5} & \multicolumn{2}{|l|}{6} \\
\hline & & $w^{a}$ & $\%$ & w & $\%$ & w & $\%$ & w & $\%$ & w & $\%$ & w & $\%$ \\
\hline$P W G_{d}$ & 15.29 & 1.000 & 45 & 1.000 & 66 & 1.000 & 44 & 1.000 & 57 & 1.000 & 33 & 1.000 & 23 \\
\hline$P W G_{m}$ & 7.36 & 1.000 & 22 & 0.915 & 29 & 1.000 & 21 & 0.142 & 4 & 1.000 & 16 & -1.905 & 22 \\
\hline CWT & 37.23 & -0.310 & 34 & -0.028 & 5 & -0.320 & 34 & -0.285 & 39 & -0.650 & 52 & -0.963 & 55 \\
\hline
\end{tabular}

${ }^{a}$ w's are the index coefficients to be applied to the estimated breeding values (EBV) for direct and maternal effects on preweaning gain ( $P W G_{d}$ and $P W G_{m}$, respectively) and on cow weight (CWT).

Table 3 shows correlations among the indexes that were developed for the sires that had progeny with records in the data. Average accuracies of the EBV for these sires were $0.63,0.70$, and 0.42 for CWT, $A D G_{d}$, and $A D G_{m}$, respectively. The EBV ranged from -38.0 to 89.6 for CWT, -0.051 to 0.470 for $A D G_{d}$, and 0.095 to 0.229 for $A D G_{m}$. Differences between the Pearson and Spearman correlation coefficients appear to be trivial and are ignored in this discussion. If Robertson's (1959) rule of thumb that correlations $>0.8$ are indicative of similar phenomena is adopted as an aid to interpreting these results, the two unrestricted indexes and the restricted indexes that seek to increase output while holding input constant would be judged similar and very different from those indexes that seek to reduce the use of inputs while maintaining the level of production. Again, these results support the contention of Dinkel \& Brown (1978) that cow efficiency is underpinned by cow productivity. Granted, for Indexes 2 and 4, the equation for prediction of TDN comes from the same data that were used by Dinkel \& Brown (1978) and thus this conclusion might be expected. However, Indexes 1 and 3 are entirely independent of those data. Further, because of the loss in efficiency associated with restricted selection indexes, use of a selection index that is consistent with the econometric definition of efficiency and seeks to increase output and reduce input simultaneously is recommended.

In summary, components of cow efficiency were found to be heritable and correlated. Thus, a system of multiple trait genetic evaluation is recommended. The evaluation of selection indexes that are indicative of cow efficiency found that not all indexes were equivalent. Use of a multiple trait selection index that is consistent with simultaneously increasing output and reducing input is recommended. 
Table 3 Correlations ${ }^{a}$ among alternative indexes of cow efficiency using the estimated breeding values for sires $(\mathrm{N}=350)$ that had progeny with records in the data

\begin{tabular}{lcccccc}
\hline Index & 1 & 2 & 3 & 4 & 5 & 6 \\
\hline 1 & & 0.83 & 1.00 & 0.88 & 0.50 & -0.07 \\
2 & 0.83 & & 0.81 & 0.81 & -0.07 & -0.46 \\
3 & 1.00 & 0.81 & & 0.87 & 0.53 & -0.04 \\
4 & 0.88 & 0.81 & 0.88 & & 0.34 & 0.15 \\
5 & 0.45 & -0.07 & 0.47 & 0.32 & & 0.62 \\
6 & -0.08 & -0.45 & -0.06 & 0.12 & 0.61 & \\
\hline
\end{tabular}

\footnotetext{
${ }^{a}$ Values above the diagonal are Pearson correlation coefficients and values below the diagonal are Spearman (rank) correlation coefficients
}

\section{Acknowledgements}

The authors thank the Pinzgauer breeders of South Africa for collection of pedigree and phenotype data that was used for this study.

\section{Authors' contributions}

The study was conceived by MDM, based on the MSc thesis work of MCM, which was produced under the supervision of MMS and FWCN. FJJ oversaw the preparation of the data. MDM led the analyses of data and interpretation of results with assistance from MCM and MMS. The manuscript was initially drafted by MDM in collaboration with MCM and MMS. All authors read and approved the final manuscript.

\section{Conflict of Interest}

The authors declare that they have no conflicts of interest with regard to this work.

\section{References}

Anderson, V.L., Jost, L., Dinkel, C.A. \& Brown, M.A., 1983. Prediction of total digestible nutrient requirement of beef cows in northern climates. J. Anim. Sci. 56, 271-279.

Assan, N., 2012. Genetic improvement and utilization of indigenous cattle breeds for beef production in Zimbabwe: Past, present and future prospects. Scientific J. Agric. 1, 1-13.

Boldman, K.G., Kriese, L.A, Van Vleck, L.D. \& Kachman, S.D., 1993. A manual for use of MTDFREML. USDA-ARS, Clay Center, Nebraska.

Brinks, J.S., Clark, R.T, Kieffer, N.M. \& Urick, J.J., 1964. Estimates of genetic, environmental and phenotypic parameters in range Hereford females. J. Anim. Sci. 20, 903.

Davis, M.E., Rutledge, J.J., Cundiff, L.V. \& Hauser, E.R., 1983. Life cycle efficiency of beef production: II. Relationship of cow efficiency ratios to traits of the dam and progeny weaned. J. Anim. Sci. 57, 852-866.

Dickerson, G.E., \& Grimes, J.C., 1947. Effectiveness of selection for efficiency of gain in Duroc swine. J. Anim. Sci. 6 , 265-287.

Dinkel, C.A. \& Brown, M.A., 1978. An evaluation of the ratio of calf weight to cow weight as an indicator of cow efficiency. J. Anim. Sci. 46, 614-617.

Ferrell, C.L. \& Jenkins, T.G., 1984. Energy utilization by mature, nonpregnant, nonlactating cows of different types. J. Anim. Sci. 58, 234-243.

Frahm, R.R. \& Marshall, D.M., 1985. Comparisons among two-breed cross cow groups. I. Cow productivity and calf performance to weaning. J. Anim. Sci. 61, 844-855.

Gunsett, F.C., 1986. Problems associated with selection for traits defined as a ratio of two component traits. Proc. 3rd World Congr. Genet. Appl. Livest. Prod. XI, 437-440.

Hetzel, D.J.S. \& Seifert, G.W., 1986. Breeding objectives and selection traits for extensive beef cattle production in the tropics. In: G.E. Dickerson \& R.K. Johnson (ed). Proc. 3rd World Cong. Genet. Appl. Livestk. Prod.

Iwaisaki, I., 1989. Distributional and genetic properties of and selection for ratio indexes. Ph.D. thesis. Univ. of Guelph. Guelph, Ontario, Canada.

Kennedy, B.W., Van der Werf, J.H.J. \& Meuwissen, T.H.E., 1993. Genetic and statistical properties of residual feed intake. J. Anim. Sci. 71, 3239-3250.

Kirkpatrick, B.W., Dinkel, C.A., Rutledge, J.J. \& Hauser, E.R., 1985. Prediction equations of beef cow efficiency. J. Anim. Sci. 60, 964-969.

Laske, C.H., Teixeira, B.B.M., Dionello, N.J.L., \& Cardoso, F.F., 2012. Breeding objectives and economic values for traits of low input family-based beef cattle production system in the State of Rio Grande do Sul. Revista Brasileira de Zootecnia, 41, 298-305.

Lin, C.Y., 1980. Relative efficiency of selection methods for improvement of feed efficiency. J. Dairy Sci. 63, 491-494.

MacNeil, M.D., 2005. Evaluation of the ratio of calf weaning weight to cow weight. J. Anim. Sci. 83, 794-802. 
MacNeil, M.D. \& Mott, T.B., 2000. Using genetic evaluations for growth and maternal gain from birth to weaning to predict energy requirements of Line 1 Hereford beef cows.J. Anim. Sci. 78, 2299-2304.

MacNeil, M.D. \& Newman, S., 1994. Selection indices for Canadian beef production using specialized sire and dam lines. Can. J. Anim. Sci. 74, 419-424.

MacNeil, M.D., Leesburg, V.R. \& Mott, T.B., 2006. Validating the breeding value for maternal preweaning gain in beef cattle with measured milk production. S. Afr. J. Anim. Sci. 36, 1-4.

MacNeil. M.D., Newman, S., Enns, R.M. \& Stewart-Smith, J., 1994. Relative economic values for Canadian beef production using specialized sire and dam lines. Can. J. Anim. Sci. 74, 411-417.

Maule, J.P., 1973. The role of the indigenous breeds for beef production in Southern Africa. S. Afr. J. Anim. Sci. 3, 111130.

Meyer, K.M., Carrick, J. \& Donnelly, B.J.P. 1994. Genetic parameters for milk production of Australian beef cows and weaning weight of their calves. J. Anim. Sci. 72, 1155-1165.

Miller, S.P., \& Wilton, J.W. 1999. Genetic relationships among direct and maternal components of milk yield and maternal weaning gain in a multibreed beef herd. J. Anim. Sci. 77, 1155-1161.

Morley, F.H.W., 1955. Selection for economic characters in Australian Merino Sheep. V. Further estimates of phenotypic and genetic parameters. Australian J. Agr. Res. 6, 77-90.

Mummed, Y.Y. 2013. Correlation between milk suckled and growth of calves of Ogaden cattle at one, three and six months of age, east Ethiopia. SpringerPlus, 2, 302. http://doi.org/10.1186/2193-1801-2-302.

Mwansa, P.B., Crews, Jr., D.H., Wilton, J.W. \& Kemp, R.A., 2002. Multiple trait selection for maternal productivity in beef cattle. J. Anim. Breed. Genet. 119, 391-399.

Pravia, M.I., Ravagnolo, O., Urioste, J.I. \& Garrick, D.J., 2014. Identification of breeding objectives using a bioeconomic model for a beef cattle production system in Uruguay. Livestk. Sci. 160, 21-28.

Robertson, A., 1959. The sampling variance of the genetic correlation coefficient. Biometrics 15, 469-485.

Scholtz, M.M.\& Theunissen, A. 2010. The use of indigenous cattle in terminal cross-breeding to improve beef cattle production in Sub-Saharan Africa. Anim. Genet. Res. 46, 33-39.

Walmsley, B.J., Lee, S.J., Parnell, P.F. \& Pitchford, W.S., 2016. A review of factors influencing key biological components of maternal productivity in temperate beef cattle. Anim. Prod. Sci. http://dx.doi.org/10.1071/AN12428. 